\title{
IMPLEMENTASI STANDAR NASIONAL PERPUSTAKAAN DI SMA NEGERI DALAM MENINGKATKAN KUALITAS LAYANAN PENDIDIKAN (Studi Pada Perpustakaan Sekolah SMAN 3 Kota Malang)
}

\author{
'Lestari Eko Wahyudi, ${ }^{2}$ Aulia Puspaning Galih, ${ }^{3}$ Rendra Eko Wismanu \\ 'Administrasi Pendidikan, Universitas Brawijaya \\ ${ }^{2}$ IImu Perpustakaan, Universitas Brawijaya \\ ${ }^{3}$ Administrasi Publik, Universitas Brawijaya \\ Email : lestariekow@ub.ac.id \\ Jalan MT. Haryono 163, Malang 6514,Indonesia
}

\begin{abstract}
This study aims to describe and analyze the application of national library standards in improving the quality of education services at SMAN 3 Malang. The research method used is a qualitative method approach with data collection techniques of observation, interviews and documentation. The data analysis used was developed by Robert K. Yin which includes several stages, including: compilation, assembling, reassembling, data interpretation, and drawing conclusions. The conclusion of this study shows that SMAN 3 Malang City has attempted to manage libraries in accordance with National Library Regulation Number 12 of 2017 concerning National Standards for High School Libraries which include: collection standards, facilities and infrastructure standards, service standards, library staff standards, and library management standards., although there are still some standards that have not been met due to inadequate quantity and qualification of library staff and budget constraints. In addition, the location of the school library at SMAN 3 Malang which is less strategic is one of the inhibiting factors in meeting these standards.
\end{abstract}

Keywords: implementation; library; national standard of high school library

\begin{abstract}
Abstrak
Penelitian ini bertujuan untuk mendeskripsikan dan menganalisis penerapan standar nasional perpustakaan dalam peningkatan mutu layanan pendidikan di SMAN 3 Malang. Metode penelitian yang digunakan adalah pendekatan metode kualitatif dengan teknik pengumpulan data observasi, wawancara dan dokumentasi. Analisis data yang digunakan dikembangkan oleh Robert K. Yin yang meliputi beberapa tahapan antara lain: kompilasi, assembling, reassembling, interpretasi data, dan penarikan kesimpulan. Kesimpulan penelitian ini menunjukkan bahwa SMAN 3 Kota Malang telah berupaya mengelola perpustakaan sesuai dengan Peraturan Perpusnas Nomor 12 Tahun 2017 tentang Standar Nasional Perpustakaan Sekolah Menengah Atas yang meliputi: standar koleksi, standar sarana dan prasarana, pelayanan standar, standar staf perpustakaan, dan standar manajemen perpustakaan, meskipun masih ada beberapa standar yang belum terpenuhi karena kuantitas dan kualifikasi staf perpustakaan yang tidak memadai serta keterbatasan anggaran. Selain itu, letak perpustakaan sekolah di SMAN 3 Malang yang kurang strategis menjadi salah satu faktor penghambat dalam memenuhi standar tersebut.
\end{abstract}

Kata Kunci: Implementasi; Perpustakaan; standar nasional perpustakaan SMA 


\section{Journal Publicuho}

ISSN 2621-1351 (online), ISSN 2685-0729 (print)

Volume 5 Number 1 (February - April 2022) pp. 50-62

Accredited SINTA SK.NOMOR 28/E/KPT/2019

Open Access at:http://ojs.uho.ac.id/index.php/PUBLICUHO/index

\section{PENDAHULUAN}

Salah satu sarana untuk memperoleh sumber informasi yang sangat mudah yang tersedia disekitar lingkungan kita yaitu perpustakaan baik Perpustakaan Nasional, Perpustakaan Daerah, Perpustakaan Sekolah dan lainnya. Sebagai seorang pelajar tentu menyadari bahwa keberadaan perpustakaan sekolah sebagai pusat sumber belajar khususnya membaca sangat penting karena akan membantu para pelajar maupun guru ketika di sekolah. Keberadaan perpustakaan umum juga mampu memberikan kebermanfaatan bagi masyarakat secara luas untuk mencari bahan ilmu atau sumber belajar. Sehingga, perpustakaan harus mampu dikelola dengan baik dan mampu memberikan pelayanan yang terbaik baik pengunjung baik perpustakaan sekolah maupun perpustakaan umum.

Berdasarkan data statistik Perpustakaan Nasional (2020) diketahui bahwa jumlah perpustakaan umum sebanyak 88.468 unit, perpustakaan sekolah sebanyak 1.677 unit, perpustakaan perguruan tinggi sebanyak 3.388 unit dan perpustakaan khusus sebanyak 1.478 unit yang tersebar diseluruh Indonesia. Khusus di Provinsi Jawa Timur jumlah perpustakaan yang ada saat ini yaitu: 373 unit perpustakaan umum, 228 unit perpustakaan khusus, 242 unit perpustakaan perguruan tinggi dan 10,896 unit perpustakaan sekolah (Perpusnas.go.id, 2020).

Menurut data Kemendikbud (2020) bahwa tidak semua sekolah pada seluruh jenjang pendidikan memiliki perpustakaan sekolah. Sebagai contoh jenjang pendidikan SD hanya $55 \%$ sekolah yang memiliki perpustakaan, SMP $69 \%$ sekolah yang memiliki perpustakaan, SMA hanya 70\%, SMK 54\% dan PLB hanya $45 \%$ yang memiliki perpustakaan sekolah. Sedangkan di Provinsi Jawa Timur untuk jenjang pendidikan SD hanya sekitar $54 \%$ sekolah yang memiliki perpustakaan, SMP 70\% sekolah, SMA 66\% sekolah, SMK 50\% sekolah dan PLB 40\% sekolah (kemdikbud.go.id, 2020).

Berdasarkan data Perpustakaan Nasional (2020) diketahui bahwa di wilayah Jawa Timur tidak ada satupun wilayah/ daerah yang memiliki nilai indeks kecukupan perpustakaan yang lebih dari 50 dimana rata-rata nilai indeks kecukupan perpustakaan yaitu di bawah 7 (tujuh). Sebagai contoh Kota Surabaya memiliki indeks kecukupan perpustakaan 2,91 (cukup), Kab. Sidoarjo 2,03 (cukup), Kota Batu 4,03 (cukup), Kab. Malang 3,36 (cukup) dan Kota Malang 3,90 (cukup) (Perpusnas.go.id, 2020). Model Analisis Indeks Kecukupan Perpustakaan Berbasis ini adalah model yang dipergunakan untuk mengetahui daerah mana saja yang jumlah perpustakaannya kurang, cukup maupun memadai. Sistem ini bermanfaat untuk membantu pemerintah dalam merencanakan pembangunan perpustakaan baru di wilayah yang kurang memadai (Hidayah, Susetyo, \& Kusumah, 2019). 
ISSN 2621-1351 (online), ISSN 2685-0729 (print)

Volume 5 Number 1 (February - April 2022), pp.50-62

DOI:http://dx.doi.org/10.35817/jpu.v5i1.23714

Lestari Eko Wahyudi, et.al

Ketika kecukupan perpustakaan disuatu wilayah masih belum memadai diharapkan pada sisi kualitas perpustakaan yang tersedia saat ini dapat ditingkatkan untuk mendorong peningkatan kualitas SDM. Selain itu, kondisi masing-masing perpustakaan bervariatif tergantung kondisi geografis wilayah, kondisi keuangan/ anggaran dan ketersediaan sumberdaya pengelola perpustakaan yang berkompeten. Dibutuhkan standarisasi perpustakaan sekolah untuk mampu memberikan pelayanan yang baik dan mampu mewujudkan pemerataan kualitas perpustakaan sekolah diseluruh wilayah Indonesia.

Berdasarkan Peraturan Kepala Perpustakaan Nasional Republik Indonesia Nomor 12 Tahun 2017 Tentang Standar Nasional Perpustakaan Sekolah Menengah Atas/ Madrasah Aliyah dan Peraturan Pemerintah Republik Indonesia Nomor 24 Tahun 2014 Tentang Pelaksanaan Undang-Undang Nomor 43 Tahun 2007 Tentang Perpustakaan menyebutkan bahwa Standar Nasional Perpustakaan dibutuhkan sebagai dasar untuk kriteria minimal yang digunakan sebagai acuan penyelenggaraan, pengelolaan, dan pengembangan perpustakaan di wilayah hukum Negara Kesatuan Republik Indonesia. Dengan regulasi ini, maka setiap perpustakaan baik umum maupun sekolah harus memiliki standar minimal pelayanan yang mengacu pada regulasi tersebut beserta turunannya. Lebih lanjut dijelaskan bahwa Standar Nasional Perpustakaan terdiri atas: (a) Standar koleksi perpustakaan; (b) Standar sarana dan prasarana; (c) Standar pelayanan perpustakaan; (d) Standar tenaga perpustakaan; (e) Standar penyelenggaraan; dan (f) Standar pengelolaan.

Perpustakaan sekolah dan umum diharapkan mampu memenuhi standar nasional tersebut untuk menunjang dan meningkatkan kualitas pelayanan kepada para pengunjung, yang pada akhirnya diharapkan dapat memberikan dampak pada perubahan budaya masyarakat untuk semakin gemar membaca dan mencari sumber informasi. Kondisi tersebut ketika sudah menjadi budaya pada setiap masyarakat secara tidak langsung akan membawa dampak pada peningkatan kualitas sumberdaya manusia.

Oleh karena itu, peneliti tertarik untuk mengkaji bagaimana perpustakaan sekolah menengah atas yang ada di Kota Malang mampu mengimplementasikan peraturan tersebut dalam rangka memberikan pelayanan yang terbaik untuk mendukung peningkatan kualitas sumberdaya manusia di lingkungan sekolah. Mengingat Kota Malang merupakan Kota Pendidikan yang memiliki banyak fasilitas pendidikan mulai dari pendidikan dasar hingga tinggi. SMAN 3 Malang merupakan salah satu contoh SMAN yang memiliki prestasi dan peringkat teratas untuk kategori SMAN di wilayah Kota Malang. Dimana nilai capaian ujian nasional memiliki rata-rata 79,46 tahun pelajaran 2018/2019 (Kemdikbud.go.id, 2020). Selain itu, sudah menjadi rahasia umum bahwa SMAN 3 Malang merupakan SMA tujuan prioritas bagi para pelajar yang memiliki kemampuan akademik diatas rata-rata dan kemampuan finansial. Sehingga, menjadi hal yang wajib bagi SMAN 3 Malang untuk 


\section{Journal Publicuho}

ISSN 2621-1351 (online), ISSN 2685-0729 (print)

Volume 5 Number 1 (February - April 2022) pp. 50-62

Accredited SINTA SK.NOMOR 28/E/KPT/2019

Open Access at:http://ojs.uho.ac.id/index.php/PUBLICUHO/index

DOl: http://dx.doi.org/10.35817/jpu.v5il.23714

menyediakan sarana dan prasarana penunjang pendidikan yang berkualitas termasuk di Perpustakaan Sekolah.

Oleh karena itu, ada tiga hal yang dikaji dalam artikel ini: (a) Bagaimana pelaksanaan Standar Nasional Perpustakaan Sekolah di SMAN 3 Malang? (b) Bagaimana pelaksanaan Standar Nasional Perpustakaan Sekolah di SMAN 3 Malang dalam meningkatkan kualitas pelayanan pendidikan? (c) Faktor yang mempengaruhi pelaksanaan Standar Nasional Perpustakaan di SMAN 3 Malang? Penelitian ini diharapkan mampu memberikan manfaat dalam meningkatkan kualitas pelayanan perpustakaan untuk mewujudkan sumberdaya manusia yang berkualitas.

\section{Kajian Pustaka}

\section{Implementasi Kebijakan}

Kebijakan adalah hal/ Tindakan yang dipergunakan sebagai sarana untuk mengatur, mengelola, mengendalikan permasalahan yang berkaitan dengan masyarakat dan negara. Kebijakan dirumuskan untuk memberikan solusi terhadap berbagai permasalahan yang dihadapi oleh Pemerintah untuk menghadirkan dampak yang positif (Birkland, 2016). Senada dengan Birkland, Chandler dan Plano (1988) menjelaskan bahwa kebijakan merupakan Tindakan yang strategis untuk memanfaatkan sumberdaya sebagai alat untuk menguraikan masalah publik/ pemerintah. Implementasi menurut Grindle (1980) merupakan proses administrative untuk mencapai tujuan yang ditetapkan oleh pemerintah baik terkait kegiatan ataupun anggaran yang akan didistribusikan. Keban (2014) mendifinisikan implementasi sebagai aktivitas administrator untuk merealisasikan program untuk mengorganisir dan menerapkan kebijakan yang telah ditetapkan. Kebijakan akan menghasilkan dampak positif apabila diimplementasikan dengan benar dan tepat. Sehingga, keberhasilan dalam implementasi kebijakan dapat dilihat dari 2 aspek yaitu proses dan capaian hasil (Agustino, 2016).

Lebih lanjut, menurut argumen Grindle (dalam Elwan.L.O.M, 2011: 22) bahwa keberhasilan suatu implementasi kebijakan publik amat ditentukan oleh derajat dapat tidaknya kebijakan itu diterapkan atau implementabilitas (implementability) dari kebijakan tersebut. Implementabilitas ini dapat dilihat dari aspek isi kebijakan (content of policy) dan aspek konteks implementasi kebijakan (contexs of policy implementation). (Supriadin et al., 2020).

\section{Standar Nasional Perpustakaan Sekolah Menengah Atas/Madrasah Aliyah}

Kepala Perpustakaan Republik Indonesia telah membuat Peraturan Kepala Perpustakaan Nasional Republik Indonesia Nomor 12 Tahun 2017 Tentang Standar Nasional Perpustakaan Sekolah Menengah Atas/ Madrasah Aliyah (Perpusnas.go.id, 2017), oleh karena itu setiap penyelenggara dan/atau pengelola Perpustakaan Sekolah Menengah 
ISSN 2621-1351 (online), ISSN 2685-0729 (print)

Volume 5 Number 1 (February - April 2022), pp.50-62

DOI:http://dx.doi.org/10.35817/jpu.v5i1.23714

Lestari Eko Wahyudi, et.al

Atas/Madrasah Aliyah wajib berpedoman pada Standar Nasional Perpustakaan Sekolah Menengah Atas/Madrasah Aliyah yang meliputi standar berikut ini:

Standar Koleksi Perpustakaan

Perpustakaan Sekolah Menengah Atas harus memiliki jenis koleksi Koleksi perpustakaan meliputi: (1) karya cetak; (2) terbitan berkala; dan (3) audio visual, rekaman suara, rekaman video, sumber elektronik. Untuk jumlah koleksi, perpustakaan wajib memperkaya koleksi dan menyediakan bahan perpustakaan dalam berbagai bentuk media dan format paling sedikit: (a) menyediakan koleksi buku teks wajib dalam jumlah yang mencukupi untuk melayani semua peserta didik dan pendidik; (b) buku pengayaan dengan perbandingan $70 \%$ nonfiksi dan 30\% fiksi, dengan ketentuan bila 3 s.d. 6 rombongan belajar jumlah buku sebanyak 1.000 judul, 7 s.d. 12 rombongan belajar jumlah buku sebanyak 1.500 judul, 13 s.d. 18 rombongan belajar jumlah buku sebanyak 2.000 judul, 19 s.d. 27 rombongan belajar jumlah buku sebanyak 2.500 judul. Perpustakaan menambah koleksi buku per tahun dengan ketentuan semakin besar jumlah koleksi semakin kecil persentase penambahan koleksinya (1.000 judul penambahan sebanyak 10\%; 1.500 judul penambahan sebanyak 8\%; 2.000 judul sampai dan seterusnya penambahan sebanyak 6\%).

Perpustakaan juga melanggan paling sedikit 3 judul majalah dan 3 judul surat kabar. Koleksi referensi paling sedikit meliputi kamus bahasa Indonesia, kamus bahasa daerah, 5 jenis kamus bahasa asing, kamus subjek, ensiklopedia, buku statistik daerah, direktori, peraturan perundang-undangan, atlas, peta, biografi tokoh, dan kitab suci.

Bahan pustaka perpustakaan dideskripsikan, diklasifikasi, diberi tajuk subjek dan disusun secara sistematis dengan mengacu pada: (1) pedoman deskripsi bibliografis dan penentuan tajuk entri utama; (2) bagan klasifikasi DEWEY (Dewey Decimal Classification); dan (3) pedoman tajuk subjek.

Perpustakaan melakukan cacah ulang (stock opname) dan penyiangan koleksi perpustakaan paling sedikit 3 (tiga) tahun sekali. Perpustakaan melakukan perawatan bahan perpustakaan dengan cara pengendalian kondisi ruangan berupa menjaga kecukupan cahaya dan kelembaban udara. Perpustakaan melakukan perbaikan bahan perpustakaan yang rusak paling sedikit 1 tahun sekali.

Sarana dan Prasarana Gedung

Lokasi perpustakaan berada di pusat kegiatan pembelajaran dan mudah dilihat serta mudah dijangkau oleh peserta didik, pendidik dan tenaga kependidikan. Luas gedung perpustakaan sekolah paling sedikit $0,4 \mathrm{~m}^{2} \times$ jumlah siswa, dengan ketentuan bila 3 s.d. 6 rombongan belajar luas gedung paling sedikit $72 \mathrm{~m}^{2}, 7$ s.d. 12 rombongan belajar luas gedung paling sedikit $144 \mathrm{~m}^{2}, 13$ s.d. 18 rombongan belajar luas gedung paling sedikit 216 $\mathrm{m}^{2}, 19$ s.d. 27 rombongan belajar luas gedung paling sedikit $288 \mathrm{~m}^{2}$. Area Gedung/ruang 


\section{Journal Publicuho}

ISSN 2621-1351 (online), ISSN 2685-0729 (print)

Volume 5 Number 1 (February - April 2022) pp. 50-62

Accredited SINTA SK.NOMOR 28/E/KPT/2019

Open Access at:http://ojs.uho.ac.id/index.php/PUBLICUHO/index

perpustakaan paling sedikit meliputi: (1) area koleksi; (2) area baca; (3) area kerja; dan (4) area multimedia.

Pelayanan Perpustakaan

Perpustakaan menyediakan pelayanan kepada pemustaka paling sedikit 8 (delapan) jam per hari kerja. Jenis pelayanan perpustakaan Jenis pelayanan perpustakaan paling sedikit meliputi: (1) pelayanan sirkulasi; (2) pelayanan referensi; dan (3) Pelayanan literasi informasi. Perpustakaan Sekolah wajib memiliki program wajib baca di perpustakaan, selain itu perpustakaan perlu memiliki program pendidikan pemustaka paling sedikit 1 (satu) sekali. Perpustakaan memiliki program literasi informasi paling sedikit 4 (empat) kali dalam 1 (satu) tahun untuk setiap tingkatan kelas. Perpustakaan harus melakukan promosi perpustakaan, membuat laporan kegiatan pelayanan perpustakaan (statistik) paling sedikit berupa laporan bulanan dan laporan tahunan. Perpustakaan juga harus melakukan kegiatan yang terintegrasi dengan kurikulum sekolah.

Tenaga Perpustakaan

Perpustakaan dikelola oleh tenaga perpustakaan paling sedikit 1 (satu) orang. Bila perpustakaaan sekolah/madrasah memiliki lebih dari enam rombongan belajar, maka sekolah diwajibkan memiliki tenaga perpustakaan sekolah paling sedikit 2 orang. Kualifikasi tenaga perpustakaan sekolah paling rendah D-II di bidang ilmu perpustakaan dari perguruan tinggi yang terakreditasi. Setiap orang yang memiliki kualifikasi akademik paling rendah diploma dua (D-II) di luar bidang perpustakaan dari perguruan tinggi yang terakreditasi dapat menjadi pustakawan setelah lulus pendidikan dan pelatihan bidang perpustakaan.

Kepala Sekolah dapat mengangkat kepala perpustakaan apabila memiliki lebih dari 1 orang tenaga perpustakaan, memiliki lebih dari 6 (enam) rombongan belajar, dan memiliki koleksi paling sedikit 1.000 judul. Kualifikasi kepala perpustakaan adalah pustakawan yang memiliki kualifikasi akademik paling rendah Diploma dua (D-II) dalam bidang perpustakaan atau bidang lain dari perguruan tinggi yang terakreditasi.

Penyelenggaraan Perpustakaan

Struktur organisasi perpustakaan sekolah mencakup kepala perpustakaan, pelayanan teknis, pelayanan pemustaka, dan teknologi informasi dan komunikasi. Struktur perpustakaan sekolah langsung di bawah kepala sekolah. Dalam rangka menjalankan organisasi, perpustakaan sekolah membuat program kerja tahunan yang mengacu pada program kerja sekolah dalam tahun anggaran yang berjalan.

Pengelolaan Perpustakaan

Visi perpustakaan Perpustakaan Sekolah Menengah Atas/Madrasah Aliyah memiliki visi perpustakaan yang mengacu pada visi sekolah, sedangkan misi perpustakaan, yaitu: (1) 
ISSN 2621-1351 (online), ISSN 2685-0729 (print)

Volume 5 Number 1 (February - April 2022), pp.50-62

Lestari Eko Wahyudi, et.al DOl:http://dx.doi.org/10.35817/jpu.v5i1.23714

menyediakan informasi dan ide yang merupakan faktor fundamental bagi kemajuan masyarakat yang berbasis informasi dan pengetahuan; dan (2) menyediakan sarana pembelajaran bagi peserta didik agar mampu belajar sepanjang hayat dan mengembangkan daya pikir agar dapat hidup sebagai warga negara yang bertanggung jawab.

Sekolah Menengah Atas/Madrasah Aliyah menjamin tersedianya anggaran perpustakaan setiap tahun paling sedikit $5 \%$ (lima persen) dari total anggaran sekolah di luar belanja pegawai dan pemeliharaan serta perawatan gedung. Teknologi Informasi dan Komunikasi Perpustakaan Sekolah Menengah Atas/Madrasah Aliyah dalam kegiatan pelayanan dan organisasi informasi memanfaatkan teknologi informasi dan komunikasi untuk meningkatkan kinerja perpustakaan dan keperluan pemustaka.

Perpustakaan Sekolah Menengah Atas/Madrasah Aliyah membuat kebijakan tertulis meliputi komponen: koleksi, sarana prasarana, pelayanan, tenaga, penyelenggaraan, dan pengelolaan perpustakaan yang terintegrasi dengan kurikulum.

\section{Kualitas Layanan Pendidikan}

Menurut Dwiyanto (2006:56) yang dikutip dari La Ode Muhammad Elwan. (2019) bahwa pemberian pelayanan publik oleh aparatur pemerintah kepada masyarakat (publik) merupakan perwujudan dan fungsi aparatur negara sebagai pelayan masyarakat (abdi), disamping sebagai abdi negara. Dalam konteks ini masyarakatlah sebagai aktor utama (pelaku) pembangunan, sedangkan pemerintah berkewajiban untuk mengarahkan, membimbing serta menciptakan suasana yang menunjang kegiatan-kegiatan dari masyarakat tersebut. Pada kondisi ini aparatur negara dituntut untuk lebih mampu memperbaiki kinerjanya (pelayanan prima) dan diharapkan lebih mampu merumuskan konsep atau menciptakan iklim yang kondusif, sehingga sumber daya pembangunan dapat menjadi pendorong percepatan terwujudnya masyarakat yang mandiri dan sejahtera. Pelayanan yang telah menunjuk kepada aturan formal dianggap telah memenuhi sendisendi pelayanan yang baik dan aparat pelayanan dianggap telah konsisten dalam menerapkan aturan hukum pelayanan. (Muhammad Elwan, 2019)

Pelayanan merupakan kegiatan untuk memenuhi kebutuhan baik barang dan jasa kepada pihak lain/ masyarakat/ pelanggan (Hardiyansah, 2011). Pelayanan perpustakaan merupakan salah satu contoh bentuk pelayanan publik yang diselenggarakan oleh pemerintah. Dimana Undang-Undang Nomor 25 Tahun 2009 tentang Pelayanan Publik menjelaskan pelayanan publik merupakan bentuk kegiatan dalam rangka pengaturan, pembinaan, bimbingan, penyediaan fasilitas, jasa dan lainnya yang dilaksanakan oleh aparatur pemerintah sebagai upaya pemenuhan kebutuhan kepada masyarakat sesuai dengan perundangan yang berlaku. 


\section{Journal Publicuho}

ISSN 2621-1351 (online), ISSN 2685-0729 (print)

Volume 5 Number 1 (February - April 2022) pp. 50-62

Accredited SINTA SK.NOMOR 28/E/KPT/2019

Open Access at:http://ojs.uho.ac.id/index.php/PUBLICUHO/index

DOl: http://dx.doi.org/10.35817/jpu.v5il.23714

Kualitas dapat didefinisikan sebagai sesuatu yang memuaskan dan melampaui keinginan dan kebutuhan pelanggan (Ariani, 2016). Pendidikan itu adalah jasa atau pelayanan dan bukan produksi barang. Indikator kinerja jasa pelayanan adalah kepuasan pelanggan sehingga kinerja kualitas pendidikan dapat diukur dari tingkat kepuasan pelanggan (Heryani \& Rahayu, 2017). Kepuasan pelanggan adalah kondisi yang menunjukkan terpenuhinya kebutuhan, keinginan dan harapan pelanggan melalui produk yang dikonsumsi (Nasution M. N, 2001). Kualitas layanan harus dimulai dari kebutuhan pelanggan dan berakhir dengan kepuasan pelanggan serta persepsi positif terhadap kualitas Iayanan. Kualitas pelayanan (SERVQUAL) memiliki lima indikator (Gregory, 2019): (1) Tangibles (bukti terukur), menggambarkan fasilitas fisik, perlengkapan, dan tampilan dari personalia serta kehadiran para pengguna; (2) Reliability (keandalan), merujuk kepada kemampuan untuk memberikan pelayanan yang dijanjikan secara akurat dan handal; (3) Responsiveness (daya tanggap), yaitu kesediaan untuk membantu pelanggan serta memberikan perhatian yang tepat; (4) Assurance (jaminan), merupakan karyawan yang sopan dan berpengetahuan luas yang memberikan rasa percaya serta keyakinan; (5) Empathy (empati), mencakup kepedulian serta perhatian individual kepada para pengguna. Dalam dunia pendidikan yang termasuk pelanggan dalam adalah pengelolaan institusi pendidikan, misalkan manajer, guru, staf dan penyelenggara institusi. Sedangkan, pelanggan luar adalah masyarakat, pemerintah dan dunia industri. Jadi, suatu institusi pendidikan disebut bermutu apabila antara pelanggan internal dan eksternal telah terjalin kepuasan atas jasa yang diberikan (Zazin, 2011).

\section{METODOLOGI}

Penelitian ini akan dipergunakan metode kualitatif dengan jenis penelitian deskriptif, sehingga diharapkan mampu menggambarkan fenomena-fenomena dan menganalisis hubungan-hubungan yang terjadi antar fenomena-fenomena yang terkait latar belakang masalah/rumusan masalah (Sugiyono, 2017). Fokus pada penelitian ini adalah pelaksanaan standar nasional perpustakaan sekolah, pelaksanaan standar nasional perpustakaan sekolah dalam meningkatkan kualitas pelayanan pendidikan, serta faktor yang mempengaruhi pelaksanaan standar nasional perpustakaan dalam meningkatkan kualitas pelayanan pendidikan. Lokasi penelitian ini adalah SMA Negeri 3 Kota Malang yang merupakan salah satu SMA Negeri yang masuk dalam 10 besar SMA Negeri terbaik di Indonesia dengan predikat sekolah berintegritas ranking 7 di Tahun 2016 (Pradana, 2016).

Penelitian ini menggunakan teknik purposive sampling dalam pemilihan informannya. Syarat untuk menjadi informan, yaitu orang yang bergelut langsung dalam kegiatan perpustakaan dan layanan Pendidikan, dari syarat tersebut maka dipilihkan informan adalah kepala perpustakaan, tenaga perpustakaan, tenaga kependidikan, dan siswa. 
ISSN 2621-1351 (online), ISSN 2685-0729 (print)

Volume 5 Number 1 (February - April 2022), pp.50-62

Lestari Eko Wahyudi, et.al DOI:http://dx.doi.org/10.35817/jpu.v5i1.23714

\section{HASIL DAN PEMBAHASAN}

Pelaksanaan Standar Nasional Perpustakaan Sekolah Menengah Atas/Madrasah Aliyah Di

\section{SMA N 3 Kota Malang}

Standar Koleksi Perpustakaan

Jenis koleksi Perpustakaan SMAN 3 Malang terdiri dari buku siswa, majalah, surat kabar/ koran dan lainnya. Adapun jumlah jenis koleksi tersebut sebanyak 9.222 judul buku 59.206 eks yang terdiri dari buku penunjang (gol. 000-900) sebanyak 7.183 judul 29.304 eks; buku referensi sebanyak 1.564 judul, 11.413 eks; buku pegangan siswa sebanyak 84 judul, 16.031 eks; buku di Korma 391 judul, 59.206 eks. Sedangkan jumlah majalah sebanyak 4 majalah, jumlah koran sebanyak 2 koran dan beberapa jumlah tabloid sumbangan. Standar jumlah koleksi pada perpustakaan tingkat SMA minimal harus dapat menyediakan koleksi buku teks wajib dalam jumlah yang cukup untuk seluruh peserta didik dan pendidik, memiliki minimal buku pengayaan dengan perbandingan $70 \%$ non-fiksi dan 30\% fiksi, dengan ketentuan bila 3-6 rombongan belajar maka jumlah buku 1.000 judul, jika 7-12 rombongan belajar maka jumlah buku sebanyak 1.500 judul, selanjutnya untuk 13-18 rombongan belajar maka jumlah buku yaitu 2.000 judul, dan untuk 19-27 rombongan belajar maka jumlah buku sebanyak 2.500 judul. Standar koleksi lainnya yaitu perpustakaan SMA paling sedikit harus berlangganan 3 judul majalah dan 3 judul surat kabar. Sehingga, dapat dikatakan bahwa kurang adanya kesesuaian antara jumlah koleksi di Perpustakaan SMAN 3 Kota Malang dengan standar yang telah ditetapkan.

Adapun terkait bahan perpustakaan referensi, diketahui bahwa Perpustakaan SMAN 3 Kota Malang memiliki berbagai jenis buku referensi meliputi: Buku Bahasa Jawa, Bahasa Inggris, Bahasa Perancis dan Bahasa Jerman. Selain itu, setiap tahun Perpustakaan SMAN 3 Malang secara rutin melaksanakan cacah ulang dan penyiangan koleksi perpustakaan yang sudah tidak layak, melakukan perawatan bahan perpustakaan guna menjaga perpustakaan agar nyaman, rapi dan memiliki kelembaban udara yang baik dan setiap tahun pula melakukan pengolahan bahan perpustakaan.

Standar Sarana Dan Prasarana Perpustakaan

Luas gedung perpustakaan SMAN 3 Kota Malang adalah $190 \mathrm{~m}^{2}(19 \mathrm{~m} \times 10 \mathrm{~m})$. SMAN 3 Kota Malang memiliki rombongan belajar \pm 30 (kelas $X, X I$ dan XII dan masing-masing angkatan memiliki 10 rombongan belajar), maka paling sedikit luas gedung untuk perpustakaan adalah $288 \mathrm{~m}^{2}$. Perpustakaan SMAN 3 Kota Malang terdapat area koleksi berbagai jenis buku yang disusun rapi dalam rak-rak tingkat, memiliki area baca yang disediakan sebagai tempat siswa untuk membaca buku di perpustakaan, dan memiliki area untuk petugas perpustakaan melaksanakan pekerjaannya dan memberikan pelayanan kepada siswa. Selain itu, perpustakaan SMAN 3 Kota Malang memiliki sarana yang disesuaikan dengan koleksi dan pelayanan, untuk menjamin keberlangsungan fungsi 


\section{Journal Publicuho}

ISSN 2621-1351 (online), ISSN 2685-0729 (print)

Volume 5 Number 1 (February - April 2022) pp. 50-62

Accredited SINTA SK.NOMOR 28/E/KPT/2019

Open Access at:http://ojs.uho.ac.id/index.php/PUBLICUHO/index

DOI: http://dx.doi.org/10.35817/jpu.v5i1.23714

perpustakaan dan kenyamanan. Lokasi perpustakaan SMAN 3 Kota Malang berada di lantai 3 sekolah, tidak mudah dilihat dan sulit dijangkau karena lokasi yang kurang strategis dari peserta didik, pendidik maupun tenaga kependidikan.

Standar Pelayanan Perpustakaan

Waktu pelayanan di perpustakaan SMAN 3 Kota Malang di mulai pada pukul 07.00 WIB s/d pukul 15.15 WIB. Jenis pelayanan yang ada di perpustakaan SMAN 3 Kota Malang terdiri dari layanan peminjaman dan pengembalian buku (sirkulasi), layanan penelusuran, layanan referensi dan layanan internet. Dari hasil wawancara menunjukkan bahwa perpustakaan SMAN 3 Kota Malang belum mengimplementasikan program pendidikan pemustaka, program wajib baca di perpustakaan, dan program literasi informasi yang berkelanjutan. Perpustakaan SMAN 3 Kota Malang telah melakukan promosi salah satunya daftar buku baru melalui akun media sosial Instagram perpustakaan SMAN 3 Kota Malang. Perpustakaan SMAN 3 Kota Malang memiliki laporan kegiatan pelayanan perpustakaan (statistik), salah satunya berupa laporan tahunan. SMAN 3 Kota Malang belum mengadakan kerjasama, baik dengan perpustakaan sekolah lain, perpustakaan umum, organisasi perpustakaan, maupun lembaga lain atau yayasan lain. Sebelum kegiatan pengadaan koleksi, pihak perpustakaan akan melakukan koordinasi dengan pihak guru berkaitan dengan bahan ajar yang dibutuhkan. Beberapa guru mata pelajaran seperti Fisika, Biologi, Bahasa Indonesia, Bahasa Jawa, Bahasa Perancis, dan Bahasa Jerman terkadang melakukan kegiatan pembelajaran di perpustakaan.

Standar Tenaga Perpustakaan

Perpustakaan SMAN 3 Kota Malang memiliki 2 tenaga perpustakaan, yaitu pustakawan dan non pustakawan. Hasil FGD yang dilakukan peneliti dengan pihak perpustakaan SMAN 3 Kota Malang menyebutkan, satu tenaga pustakawan di SMAN 3 Kota Malang memiliki kualifikasi akademik Strata Satu (S-1) bidang perpustakaan dari perguruan tinggi terakreditasi, yaitu Iulusan dari Universitas Negeri Malang. Sedangkan untuk satu tenaga non-pustakawan yang ada, merupakan hasil dari perputaran tenaga kerja di lingkup SMAN 3 Kota Malang itu sendiri yang belum memiliki kualifikasi akademik bidang perpustakaan sesuai dengan ketentuan yang ada. Hal ini menunjukkan bahwa perpustakaan SMAN 3 Kota Malang hanya memiliki satu pegawai perpustakaan yang berkualifikasi akademik bidang perpustakaan. Sedangkan kepala perpustakaan di SMAN 3 Kota Malang yang diperoleh peneliti dari data primer hasil FGD, dikatakan bahwa kepala perpustakaan SMAN 3 Kota Malang saat ini merupakan guru mata pelajaran Geografi. Selain itu juga disebutkan jika kepala perpustakaan SMAN 3 Kota Malang saat ini, belum pernah mengikuti kegiatan pelatihan atau seminar tentang perpustakaan dan belum memiliki kualifikasi pendidikan ilmu perpustakaan. 
ISSN 2621-1351 (online), ISSN 2685-0729 (print)

Volume 5 Number 1 (February - April 2022), pp.50-62

Lestari Eko Wahyudi, et.al DOI:http://dx.doi.org/10.35817/jpu.v5i1.23714

Standar Penyelenggaraan Perpustakaan

Perpustakaan SMA N 3 Malang telah didirikan sejak tahun 1953, sejak 2006 telah melakukan proses otomasi perpustakaan. Perpustakaan SMAN 3 Kota Malang telah memiliki Nomor Pokok Perpustakaan (NPP). perpustakaan SMAN 3 Kota Malang memiliki stuktur organisasi yang jelas.

Standar Pengelolaan Perpustakaan

perpustakaan SMAN 3 Kota Malang memiliki visi yang mengacu pada visi sekolah. Visi dari SMAN 3 Kota Malang itu sendiri yaitu "menjadi sekolah unggul yang memiliki civitas akademika yang beriman, bertaqwa, berakhlaqul karimah, dan berprestasi serta berperan aktif dalam era global, dan peduli pada lingkungan". Sesuai dengan misi yang telah dipaparkan tersebut, perpustakaan SMAN 3 Kota Malang sudah menyediakan berbagai fasilitas untuk mendukung kegiatan belajar siswa, mulai dari buku pelajaran, buku referensi, surat kabar/majalah sampai akses internet untuk menambah informasi dan pengetahuan dalam upaya pengembangan daya pikir siswa. pihak perpustakaan SMAN 3 Kota Malang telah melakukan upaya dalam meningkatkan minat baca siswa, dengan menerapkan beberapa kegiatan seperti acara pameran buku di area sekolah dan pemberian reward kepada siswa yang melakukan peminjaman buku terbanyak dalam kurun waktu satu semester. perpustakaan SMAN 3 Kota Malang telah memiliki kebijakan pengelolaan atau tata tertib dalam perpustakaan sekolah. Hal ini menyatakan bahwa SMAN 3 Kota Malang telah memenuhi Peraturan Kepala Perpustakaan Nasional Republik Indonesia Nomor 12 Tahun 2017 tentang Standar Nasional Perpustakaan SMA/MA, yaitu adanya kebijakan pengelolaan perpustakaan secara tertulis yang mencakup koleksi perpustakaan, sarana dan prasarana perpustakaan, pelayanan, tenaga, penyelenggaraan, dan pengelolaan perpustakaan yang terintegrasi dengan kurikulum. perpustakaan SMAN 3 Kota Malang dikatakan bahwa belum ada anggaran khusus untuk pengelolaan perpustakaan. Dana untuk perpustakaan sekolah tidak dapat dipastikan jumlahnya dalam setiap waktu. Sehingga dapat dikatakan bahwa, perpustakaan SMAN 3 Kota Malang belum memiliki anggaran yang pasti sebagaimana yang disebutkan dalam Peraturan Kepala Perpustakaan Nasional Republik Indonesia Nomor 12 Tahun 2017 tentang Standar Nasional Perpustakaan SMA/MA.

\section{KESIMPULAN}

Berdasarkan hasil penelitian, maka disimpulkan bahwa SMAN 3 Kota Malang sudah berupaya mengelola perpustakaan sesuai dengan Peraturan Kepala Perpustakaan Nasional Republik Indonesia Nomor 12 Tahun 2017 tentang Standar Nasional Perpustakaan SMA/MA. Namun masih terdapat beberapa standar perpustakaan sekolah yang belum sesuai, diantaranya kurang adanya kesesuaian antara jumlah koleksi di Perpustakaan SMAN 3 Kota 


\section{Journal Publicuho}

ISSN 2621-1351 (online), ISSN 2685-0729 (print)

Volume 5 Number 1 (February - April 2022) pp. 50-62

Accredited SINTA SK.NOMOR 28/E/KPT/2019

Open Access at:http://ojs.uho.ac.id/index.php/PUBLICUHO/index

DOl: http://dx.doi.org/10.35817/jpu.v5il.23714

Malang dengan standar yang telah ditetapkan, kondisi ruang/gedung yang terlalu kecil dan luasnya tidak memenuhi jumlah dari rombongan belajar, lokasi perpustakaan yang kurang strategis, dan beberapa program seperti program wajib baca, pendidikan pemustaka, literasi informasi, kerjasama, standar tenaga perpustakaan dan juga dalam hal anggaran belum sesuai.

Sedangkan mengenai kualitas layanan pendidikan yang diberikan oleh SMAN 3 Kota Malang kepada para siswanya, baik pelayanan melalui tangible (bukti terukur), responsiveness (daya tanggap), reliability (keandalan), emphaty (empati), dan assurance (jaminan dan kepastian) dapat dikatakan cukup baik, walaupun masih terdapat ketidaksesuaian seperti halnya tenaga pustakawan di SMAN 3 Kota Malang yang belum memiliki kualifikasi akademik bidang ilmu perpustakaan sesuai standar tenaga perpustakaan. Faktor pendukung dan penghambat dalam upaya peningkatan kualitas pelayanan pendidikan di SMAN 3 Kota Malang, mencakup faktor pendukung internal seperti pihak perpustakaan atau pustakawan yang responsive, SMAN 3 Kota Malang termasuk dalam kategori SMA maju dan berprestasi. Kemudian untuk faktor pendukung eksternalnya seperti hibah dari pihak Telkom berupa e-book dan tuntutan akreditasi perpustakaan sekolah. Sedangkan untuk faktor penghambat internal diantaranya lokasi perpustakaan yang kurang strategis dan kurangnya sarana dan prasarana perpustakaan yang mendukung. Selanjutnya untuk faktor penghambat eksternal meliputi adanya dana BOS yang menjadikan biaya sekolah gratis dan wali murid yang terkadang menolak jika anaknya mendapatkan denda keterlambatan mengembalikan buku. Hal yang perlu dilakukan untuk mengatasi faktor penghambat internal maupun eksternal adalah Pemindahan lokasi perpustakaan SMAN 3 Kota Malang di lantai 1 atau yang lebih strategis dan mudah dijangkau oleh para siswa dan guru, Pengajuan dana atau hibah ke donatur atau stakeholder yang dapat berupa CSR (Corporate Social Responsibility). Selain itu, perlu adanya kolaborasi dengan institusi pendidikan tinggi yang memiliki Program Studi IImu Perpustakaan Seperti FIA UB dalam rangka meningkatkan tata kelola perpustakaan dan peningkatan kapasitas SDM pengelola perpustakaan melalui program magang dan pendampingan bagi pustakawan.

\section{REFERENSI}

Agustino, Leo. (2016). Dasar-Dasar Kebijakan Publik. Alfabeta.

Ariani, W. (2016). Manajemen Kualitas. Jurnal Managemen.

Birkland, Thomas A (2016). An Introduction to the policy process. Theories, Concept, and Models of Public Policy Making ( $4^{\text {th }}$ Edition). Routledge

Chandler, Ralph C., \& Plano, Jack C. (1988). The Public Administration Dictionary. John Wiley \& Sons.

Grindle, Merille S. (1980). Politics and Policy Implementations in the Third Word. Princetown 
University Press.

Gregory, J. L. (2019). Applying SERVQUAL: Using service quality perceptions to improve student satisfaction and program image. Journal of Applied Research in Higher Education, 11 (4), 788-799.

Hardiyansyah. 2011 . Kualitas Pelayanan Publik. Konsep, Dimensi, Indikator dan Implementasinya. Yogyakarta: Gava Media

Heryani, F., \& Rahayu, A. (2017). Pengaruh Kualitas Jasa Terhadap Kepercayaan Pelanggan Serta Implikasinya Pada Citra Perguruan Tinggi. JURNAL ILMU MANAJEMEN DAN BISNIS. https://doi.org/10.17509/jimb.v8i2.12661

Hidayah, N., Susetyo, B., \& Kusumah, F. S. F. (2019). Model Analisis Indeks Kecukupan Perpustakaan Berbasis Webgis. Prosiding Seminar Nasional Geotik 2019.

Keban, Yeremias T. (2014). Enam Dimensi Strategis Administrasi Publik: Konsep, Teori, dan Isu (Edisi Ketiga). Gava Media.

La Ode Muhammad Elwan, S. (2011). Implementasi Perda Kota Kendari No. 15 Tahun 2003 Tentang Partisipasi Masyarakat Dalam Perumusan Kebijakan Daerah Pada Penyusunan Anggaran Pendapatan Belanja Daerah Tahun 2010 (Doctoral dissertation, Universitas Gadjah Mada).

Muhammad Elwan, La Ode. "Problem Birokrasi dalam Meningkatan Pelayanan Publik pada Sekretariat Daerah Kabupaten Muna." Journal Publicuho, vol. 2, no. 2, 2019, pp. 31-42, doi:10.35817/jpu.v2i2.7223.

Nasution, M. N. 2001. Manajemen Mutu Terpadu (Total Quality Management). Jakarta: Ghalia Indonesia

Perpusnas.go.id. (2017). Peraturan Kepala Perpustakaan Nasional Republik Indonesia Nomor 12 Tahun 2017 Tentang Standar Nasional Perpustakaan Sekolah Menengah Atas/ Madrasah Aliyah. Retrieved March 3, 2020, from Perpustakaan Negara Republik Indonesia website:

https://jdih.perpusnas.go.id/file_peraturan/Perka_12_2017_SNP_Perpustakaan_SMA_Salin an.pdf

Pradana, A. (2016, January 9). SMAN 3 Malang Masuk 10 Besar Sekolah Terbaik Se-Indonesia. MalangTimes.Com. Retrieved from https://www.malangtimes.com/baca/8525/20160109/144500/sman-3-malang-masuk-10besar-sekolah-terbaik-se-indonesia

Undang-Undang Nomor 25 Tahun 2009 Tentang Pelayanan Publik

Sugiyono. (2017). Metode Penelitian Kuantitatif, Kualitatif dan R\&D. Alfabeta.

Supriadin, R., Alam, S., \& Elwan, L. O. M. (2020). IMPLEMENTASI PERATURAN WALIKOTA KENDARI NOMOR 13 TAHUN 2008 TENTANG PENATAAN PEDAGANG KAKI LIMA DI KOTA KENDARI. Journal Publicuho. https://doi.org/10.35817/jpu.v3i1.11506

Zazin, N. (2011). Gerakan Menata Mutu Pendidikan: Teori dan Aplikasi. Yogyakarta: Ar-Ruzz Media. 